\title{
Some Characterization of Normal Multi-fuzzy and Normal Multi-anti fuzzy Subgroup
}

\author{
R.Muthuraj ${ }^{1}$, S.Balamurugan ${ }^{2}$ \\ ${ }^{\text {I}}(P G$ and Research Department of Mathematics, H.H. The Rajah's College,Pudukkottai,Tamilnadu, India. \\ ${ }_{2}^{2}$ (Department of Mathematics, Velammal College of Engineering and Technology,Madurai,Tamilnadu,India.
}

\begin{abstract}
This paper is mainly concerned with a generalization of the concept of a normal multi-fuzzy subgroup and a normal multi-anti fuzzy subgroup. We introduce the concept of a normal multi-fuzzy subgroup of a multi-fuzzy subgroup and examine its basic properties. Also we introduce the concept of a normal multianti fuzzy subgroup of a multi-anti fuzzy subgroup and examine its basic properties. We use them to develop results concerning multi-fuzzy subgroups of a multi-fuzzy subgroup and multi-anti fuzzy subgroups of a multianti fuzzy subgroup.
\end{abstract}

Mathematics Subject Classification: MSC: 20N25; 03E72; 08A72

Keywords: Fuzzy set, multi-fuzzy set, fuzzy subgroup, multi-fuzzy subgroup, anti fuzzy subgroup, multi-anti fuzzy subgroup, normal multi-fuzzy subgroup, normal multi-anti fuzzy subgroup, multi-fuzzy coset.

\section{INTRODUCTION}

S.Sabu and T.V.Ramakrishnan [9] proposed the theory of multi-fuzzy sets in terms of multidimensional membership functions and investigated some properties of multi-level fuzziness. L.A.Zadeh [11] introduced the theory of multi-fuzzy set is an extension of theories of fuzzy sets. N.Palaniappan and R.Muthuraj [7] introduced the inter-relationship between the Anti fuzzy group and its Lower level subgroups. P.S.Das [1] studied the inter-relationship between the fuzzy subgroup and its level subsets. Liu, Mukharjee and Bhattacharya [2,3] proposed the concept of normal fuzzy sets. R.Muthuraj and S.Balamurugan [6] proposed the inter-relationship between the multi-fuzzy group and its level subgroups. R.Muthuraj and S.Balamurugan [4] also proposed the inter-relationship between the multi-anti fuzzy group and its lower level subgroups. In this paper we define a new algebraic structures of a normal multi-fuzzy subgroup and a normal multi-anti fuzzy subgroup.

\section{Preliminaries}

In this section, we site the fundamental definitions that will be used in the sequel.

2.1 Definition Let $X$ be any non-empty set. A fuzzy subset $\mu$ of $X$ is $\mu: X \rightarrow[0,1]$.

2.2 Definition Let $X$ be a non-empty set. A multi-fuzzy set $A$ in $X$ is defined as a set of ordered sequences: $\mathrm{A}=\left\{\left(\mathrm{x}, \mu_{1}(\mathrm{x}), \mu_{2}(\mathrm{x}), \ldots, \mu_{\mathrm{i}}(\mathrm{x}), \ldots\right): \mathrm{x} \in \mathrm{X}\right\}$, where $\mu_{\mathrm{i}}: \mathrm{X} \rightarrow[0,1]$ for all $\mathrm{i}$.

\section{Remark}

i. If the sequences of the membership functions have only $\mathrm{k}$-terms (finite number of terms), then $\mathrm{k}$ is called the dimension of A.

ii. The set of all multi-fuzzy sets in $\mathrm{X}$ of dimension $\mathrm{k}$ is denoted by $\mathrm{M}^{k} \mathrm{FS}(\mathrm{X})$.

iii. The multi-fuzzy membership function $\mu_{\mathrm{A}}$ is a function from $\mathrm{X}$ to $[0,1]^{k}$ such that for all $\mathrm{x}$ in $\mathrm{X}$,

iv. For the sake of simplicity, we denote the multi-fuzzy set

$$
\mu_{\mathrm{A}}(\mathrm{x})=\left(\mu_{1}(\mathrm{x}), \mu_{2}(\mathrm{x}), \ldots, \mu_{\mathrm{k}}(\mathrm{x})\right) \text {. }
$$

$$
\mathrm{A}=\left\{\left(\mathrm{x}, \mu_{1}(\mathrm{x}), \mu_{2}(\mathrm{x}), \ldots, \mu_{\mathrm{k}}(\mathrm{x})\right): \mathrm{x} \in \mathrm{X}\right\} \text { as } \mathrm{A}=\left(\mu_{1}, \mu_{2}, \ldots, \mu_{\mathrm{k}}\right) .
$$

2.3 Definition Let $k$ be a positive integer and let $A$ and $B$ in $M^{k} F S(X)$, where $A=\left(\mu_{1}, \mu_{2}, \ldots, \mu_{k}\right)$ and $B=\left(v_{1}, v_{2}\right.$, $\ldots, v_{\mathrm{k}}$ ), then we have the following relations and operations:

i. $\quad \mathrm{A} \subseteq \mathrm{B}$ if and only if $\mu_{\mathrm{i}} \leq v_{\mathrm{i}}$, for all $\mathrm{i}=1,2, \ldots, \mathrm{k}$;

ii. $\quad \mathrm{A}=\mathrm{B}$ if and only if $\mu_{\mathrm{i}}=v_{\mathrm{i}}$, for all $\mathrm{i}=1,2, \ldots, \mathrm{k}$;

iii. $\quad A \cup B=\left(\mu_{1} \cup v_{1}, \ldots, \mu_{k} \cup v_{k}\right)=\left\{\left(x, \max \left(\mu_{1}(x), v_{1}(x)\right), \ldots, \max \left(\mu_{k}(x), v_{k}(x)\right)\right): x \in X\right\}$;

iv. $\quad A \cap B=\left(\mu_{1} \cap v_{1}, \ldots, \mu_{k} \cap v_{k}\right)=\left\{\left(x, \min \left(\mu_{1}(x), v_{1}(x)\right), \ldots, \min \left(\mu_{k}(x), v_{k}(x)\right)\right): x \in X\right\}$; 
v. $\quad A+B=\left(\mu_{1}+v_{1}, \ldots, \mu_{k}+v_{k}\right)=\left\{\left(x, \mu_{1}(x)+v_{1}(x)-\mu_{1}(x) v_{1}(x), \ldots, \mu_{k}(x)+v_{k}(x)-\mu_{k}(x) v_{k}(x)\right): x \in X\right\}$

2.4 Definition Let $A=\left(\mu_{1}, \mu_{2}, \ldots, \mu_{k}\right)$ be a multi-fuzzy set of dimension $k$ and let $\mu_{\mathrm{i}}{ }^{\prime}$ be the fuzzy complement of the ordinary fuzzy set $\mu_{\mathrm{i}}$ for $\mathrm{i}=1,2, \ldots, \mathrm{k}$. The Multi-fuzzy Complement of the multi-fuzzy set A is a multifuzzy set $\left(\mu_{1}{ }^{\prime}, \ldots, \mu_{\mathrm{k}}{ }^{\prime}\right)$ and it is denoted by $\mathrm{C}(\mathrm{A})$ or $\mathrm{A}^{\prime}$ or $\mathrm{A}^{\mathrm{C}}$.

That is, $C(A)=\left\{\left(x, c\left(\mu_{1}(x)\right), \ldots, c\left(\mu_{k}(x)\right)\right): x \in X\right\}=\left\{\left(x, 1-\mu_{1}(x), \ldots, 1-\mu_{k}(x)\right): x \in X\right\}$, where $c$ is the fuzzy complement operation.

2.5 Definition Let $\mu$ be a fuzzy set on a group $G$. Then $\mu$ is said to be a fuzzy subgroup of $G$ if for all $x, y \in G$,

i. $\quad \mu(x y) \geq \min \{\mu(x), \mu(y)\}$

ii. $\mu\left(x^{-1}\right)=\mu(x)$

2.6 Definition A multi-fuzzy set $A$ of a group $G$ is called a multi-fuzzy subgroup of $G$ if for all $x, y \in G$,

i. $\quad \mathrm{A}(\mathrm{xy}) \geq \min \{\mathrm{A}(\mathrm{x}), \mathrm{A}(\mathrm{y})\}$

ii. $\quad \mathrm{A}\left(\mathrm{x}^{-1}\right)=\mathrm{A}(\mathrm{x})$

2.7 Definition Let $\mu$ be a fuzzy set on a group G. Then $\mu$ is called an anti fuzzy subgroup of $\mathrm{G}$ if for all $\mathrm{x}, \mathrm{y} \in \mathrm{G}$,

i. $\quad \mu(x y) \leq \max \{\mu(x), \mu(y)\}$

ii. $\quad \mu\left(x^{-1}\right)=\mu(x)$

2.8 Definition A multi-fuzzy set $A$ of a group $G$ is called a multi-anti fuzzy subgroup of $G$ if for all $\mathrm{x}, \mathrm{y} \in \mathrm{G}$,

i. $\quad \mathrm{A}(\mathrm{xy}) \leq \max \{\mathrm{A}(\mathrm{x}), \mathrm{A}(\mathrm{y})\}$

ii. $\quad \mathrm{A}\left(\mathrm{x}^{-1}\right)=\mathrm{A}(\mathrm{x})$

2.9 Definition Let $A$ and $B$ be any two multi-fuzzy sets of a non-empty set $X$. Then for all $x \in X$,

i. $\quad \mathrm{A} \subseteq \mathrm{B}$ iff $\mathrm{A}(\mathrm{x}) \leq \mathrm{B}(\mathrm{x})$

ii. $\quad \mathrm{A}=\mathrm{B}$ iff $\mathrm{A}(\mathrm{x})=\mathrm{B}(\mathrm{x})$

iii. $\quad(A \cup B)(x)=\max \{A(x), B(x)\}$

iv. $\quad(\mathrm{A} \cap \mathrm{B})(\mathrm{x})=\min \{\mathrm{A}(\mathrm{x}), \mathrm{B}(\mathrm{x})\}$

2.10 Definition Let $A$ and $B$ be any two multi-fuzzy sets of a non-empty set $X$. Then

i. $\quad \mathrm{A} \cup \mathrm{A}=\mathrm{A}, \mathrm{A} \cap \mathrm{A}=\mathrm{A}$

ii. $\quad \mathrm{A} \subseteq \mathrm{A} \cup \mathrm{B}, \mathrm{B} \subseteq \mathrm{A} \cup \mathrm{B}, \mathrm{A} \cap \mathrm{B} \subseteq \mathrm{A}$ and $\mathrm{A} \cap \mathrm{B} \subseteq \mathrm{B}$

iii. $\quad \mathrm{A} \subseteq \mathrm{B}$ iff $\mathrm{A} \cup \mathrm{B}=\mathrm{B}$

iv. $\quad \mathrm{A} \subseteq \mathrm{B}$ iff $\mathrm{A} \cap \mathrm{B}=\mathrm{A}$

2.11 Definition We define the binary operation ' $\circ$ ' on $\operatorname{MFP}(G)$, the multi-fuzzy power set of a group $G$ and the unary operation ${ }^{-1}$ on $\operatorname{MFP}(\mathrm{G})$ as follows:

$\forall \mathrm{A}, \mathrm{B} \in \mathrm{MFP}(\mathrm{G})$ and $\forall \mathrm{x} \in \mathrm{G},(\mathrm{A} \cdot \mathrm{B})(\mathrm{x})=\max \{\min \{\mathrm{A}(\mathrm{y}), \mathrm{B}(\mathrm{z}) / \mathrm{y}, \mathrm{z} \in \mathrm{G}, \mathrm{yz}=\mathrm{x}\}\}$ and $\mathrm{A}^{-1}(\mathrm{x})=\mathrm{A}\left(\mathrm{x}^{-1}\right)$. We call $\mathrm{A} \cdot \mathrm{B}$ as the product of $\mathrm{A}$ and $\mathrm{B}$ and $\mathrm{A}^{-1}$ as the inverse of $\mathrm{A}$. The binary operation '。' is associative.

\section{Normal multi-fuzzy subgroup of the multi-fuzzy subgroup}

In this section, we introduce the concept of normal multi-fuzzy subgroup of a multi-fuzzy subgroup and examine its basic properties.

3.1 Definition A multi-fuzzy subgroup $A$ of a group $G$ is called normal if for each $x \in G$,

$$
\mathrm{A}(\mathrm{x}) \leq \min _{\mathrm{g} \in \mathrm{G}}\left\{\mathrm{A}\left(\mathrm{gxg}^{-1}\right)\right\}
$$

3.2 Definition Let $A, B \in M F(G)$ and $A \subseteq B$. Then $A$ is called a normal multi-fuzzy subgroup of the multi-fuzzy subgroup $\mathrm{B}$, written as $\mathrm{A} \triangle \mathrm{B}$, if $\mathrm{A}\left(\mathrm{xyx}^{-1}\right) \geq \min \{\mathrm{A}(\mathrm{y}), \mathrm{B}(\mathrm{x})\}, \forall \mathrm{x}, \mathrm{y} \in \mathrm{G}$.

Remarks: The following statements are immediate from the above definition 3.2:

1. Every multi-fuzzy subgroup is a normal multi-fuzzy subgroup of itself. 
2. $A \in \operatorname{MFP}(G)$ is a normal multi-fuzzy subgroup of $G \Leftrightarrow A$ is a normal multi-fuzzy subgroup of the multi-fuzzy subgroup $1_{\mathrm{G}}$

Notations: The following notations to be used in this paper with the following meaning:

1. $\quad \operatorname{MF}(\mathrm{G})$ is the set of all multi-fuzzy subgroups of a group $\mathrm{G}$.

2. $\operatorname{NMF}(G)$ is the set of all normal multi-fuzzy subgroups of a group $G$.

3.3 Definition Let $\mu$ be a fuzzy subgroup of a group $\mathrm{G}$ and $\mathrm{x} \in \mathrm{G}$. The fuzzy subsets $\mu(\mathrm{e})_{\{\mathrm{x}\}^{\circ}} \mu$ and $\mu^{\circ} \mu(\mathrm{e})_{\{\mathrm{x}\}}$ are referred to as the left fuzzy coset and right fuzzy coset of $\mu$ with respect to $\mathrm{x}$ and written as $\mathrm{x} \mu$ and $\mu \mathrm{x}$, respectively.

3.4 Definition Let $A \in M F(G)$ be a multi-fuzzy subgroup of a group $G$ and $x \in G$. The multi-fuzzy sets $\left.\mathrm{A}(\mathrm{e})_{\{\mathrm{x}\}}\right\}^{\circ} \mathrm{A}$ and $\mathrm{A} \circ \mathrm{A}(\mathrm{e})_{\{\mathrm{x}\}}$ are referred to as the left multi-fuzzy coset and right multi-fuzzy coset of $\mathrm{A}$ with respect to $\mathrm{x}$ and written as $\mathrm{XA}$ and $\mathrm{Ax}$ respectively.

Remark: If $A \in \mathrm{NMF}(\mathrm{G})$ is a normal multi-fuzzy subgroup of a group $\mathrm{G}$, then the left multi-fuzzy coset $\mathrm{xA}$ is just the right multi-fuzzy coset Ax. Thus, in this case, we call xA as a multi-fuzzy coset for short.

3.1 Theorem: Let $A, B \in M F(G)$ and $A \subseteq B$. Then the following assertions are equivalent:

1. $\quad$ A is a normal multi-fuzzy subgroup of $B$

2. $\quad \mathrm{A}(\mathrm{yx}) \geq \min \{\mathrm{A}(\mathrm{xy}), \mathrm{B}(\mathrm{y})\}, \forall \mathrm{x}, \mathrm{y} \in \mathrm{G}$

3. $\quad \mathrm{A}(\mathrm{e})_{\{\mathrm{x}\}} \circ \mathrm{A} \supseteq\left(\mathrm{A} \circ \mathrm{A}(\mathrm{e})_{\{\mathrm{x}\}}\right) \cap \mathrm{B}, \forall \mathrm{x} \in \mathrm{G}$

Proof: $(1) \Rightarrow(2)$

Since $\mathrm{A}$ is a normal multi-fuzzy subgroup of $\mathrm{B}$,

$$
\begin{aligned}
\mathrm{A}(\mathrm{yx}) & =\mathrm{A}\left(\mathrm{yxyy}^{-1}\right) \\
& =\mathrm{A}\left(\mathrm{y}(\mathrm{xy}) \mathrm{y}^{-1}\right) \\
& \geq \min \{\mathrm{A}(\mathrm{xy}), \mathrm{B}(\mathrm{y})\}, \forall \mathrm{x}, \mathrm{y} \in \mathrm{G}, \text { since by the definition } 3.2 .
\end{aligned}
$$

Proof: (2) $\Rightarrow(1)$

$\mathrm{A}\left(\mathrm{xyx}^{-1}\right)=\mathrm{A}\left(\mathrm{x}\left(\mathrm{yx}^{-1}\right)\right)$

$\geq \min \left\{\mathrm{A}\left(\left(\mathrm{yx}^{-1}\right) \mathrm{x}\right), \mathrm{B}(\mathrm{x})\right\}$, since by the hypothesis(2).

$=\min \{\mathrm{A}(\mathrm{y}), \mathrm{B}(\mathrm{x})\}$

That is, A is normal multi-fuzzy subgroup of B.

That is, $\mathrm{A} \Delta \mathrm{B}$.

Proof: $(2) \Rightarrow(3)$

$\forall \mathrm{z} \in \mathrm{G},\left(\mathrm{A}(\mathrm{e})_{\{\mathrm{x}\}}{ }^{\circ} \mathrm{A}\right)(\mathrm{z})=\max \left\{\min \left\{\mathrm{A}(\mathrm{e})_{\{\mathrm{x}\}}(\mathrm{p}), \mathrm{A}(\mathrm{q})\right\} / \mathrm{pq}=\mathrm{z}\right.$ where $\left.\mathrm{p}, \mathrm{q} \in \mathrm{G}\right\}$, since by the definition 2.11.

$=\max \left\{\min \left\{\mathrm{A}(\mathrm{e})_{\{\mathrm{x}\}}(\mathrm{x}), \mathrm{A}(\mathrm{q})\right\} / \mathrm{xq}=\mathrm{z}\right\}$, since take $\mathrm{p}=\mathrm{x}$.

$=\max \left\{\min \left\{\mathrm{A}(\mathrm{e}), \mathrm{A}\left(\mathrm{x}^{-1} \mathrm{z}\right)\right\}\right\}$, since $\mathrm{A}(\mathrm{xq})=\mathrm{A}(\mathrm{z}) \Rightarrow \mathrm{A}(\mathrm{q})=\mathrm{A}\left(\mathrm{x}^{-1} \mathrm{z}\right)$.

$=\max \left\{\mathrm{A}\left(\mathrm{x}^{-1} \mathrm{z}\right)\right\}$

$=\max \left\{\mathrm{A}\left(\left(\mathrm{x}^{-1} \mathrm{z}\right)^{-1}\right)\right\}$

$=\max \left\{\mathrm{A}\left(\mathrm{z}^{-1} \mathrm{x}\right)\right\}$

$\geq \max \left\{\min \left\{\mathrm{A}\left(\mathrm{xz}^{-1}\right), \mathrm{B}\left(\mathrm{z}^{-1}\right)\right\}\right\}$, since by the hypothesis (2)

$=\max \left\{\min \left\{\mathrm{A}\left(\left(\mathrm{xz}^{-1}\right)^{-1}\right), \mathrm{B}\left(\mathrm{z}^{-1}\right)\right\}\right\}$

$=\max \left\{\min \left\{\mathrm{A}\left(\mathrm{zx}^{-1}\right), \mathrm{B}\left(\mathrm{z}^{-1}\right)\right\}\right\}$

$=\min \left\{\left(\mathrm{A} \circ \mathrm{A}(\mathrm{e})_{\{\mathrm{x}\}}\right)(\mathrm{z}), \mathrm{B}(\mathrm{z})\right\}$, since $\left(\mathrm{A} \circ \mathrm{A}(\mathrm{e})_{\{\mathrm{x}\}}\right)(\mathrm{z})=\mathrm{A}\left(\mathrm{zx}^{-1}\right)$

Hence the proof $(2) \Rightarrow(3)$

$=\left[\left(\mathrm{A} \circ \mathrm{A}(\mathrm{e})_{\{\mathrm{x}\}}\right) \cap \mathrm{B}\right](\mathrm{z})$, since by the definition of ' $\cap$ '

Proof: $(3) \Rightarrow(2)$

$\forall \mathrm{x}, \mathrm{y} \in \mathrm{G}, \quad \mathrm{A}(\mathrm{yx})=\mathrm{A}\left((\mathrm{yx})^{-1}\right)$

$=\mathrm{A}\left(\mathrm{x}^{-1} \mathrm{y}^{-1}\right)$

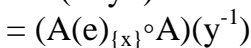

$\geq\left(\left(A \circ A(e)_{\{x\}}\right) \cap B\right)\left(y^{-1}\right)$, since by the hypothesis $(3)$

$=\min \left\{\left(\mathrm{A} \circ \mathrm{A}(\mathrm{e})_{\{\mathrm{x}\}}\right)\left(\mathrm{y}^{-1}\right), \mathrm{B}\left(\mathrm{y}^{-1}\right)\right\}$, since by the definition of ' $\mathrm{n}$ '

$=\min \left\{\mathrm{A}\left(\mathrm{y}^{-1} \mathrm{x}^{-1}\right), \mathrm{B}\left(\mathrm{y}^{-1}\right)\right\}$, since by the definition 2.11

$=\min \left\{\mathrm{A}\left((\mathrm{xy})^{-1}\right), \mathrm{B}(\mathrm{y})\right\}$

$=\min \{\mathrm{A}(\mathrm{xy}), \mathrm{B}(\mathrm{y})\}$

Hence the proof $(3) \Rightarrow(2)$ and hence the Theorem also. 
3.2 Theorem: Let $A, B \in M F(G)$. Then $A$ is a normal multi-fuzzy subgroup of $B \Leftrightarrow A_{t}$ is a normal subgroup of $\mathrm{B}_{\mathrm{t}}, \forall \mathrm{t} \in\left\{\mathrm{b} / \mathrm{b}=\left(\mathrm{b}_{1}, \mathrm{~b}_{2}, \ldots, \mathrm{b}_{\mathrm{i}}, \ldots\right), \mathrm{b}_{\mathrm{i}} \in[0,1], \forall \mathrm{i}\right.$ such that $\left.\mathrm{b} \leq \mathrm{A}(\mathrm{e})\right\}$.

Proof: ( $\Rightarrow$ part )

Suppose $\mathrm{A}$ is a normal multi-fuzzy subgroup of B.

Let $\mathrm{t} \in\left\{\mathrm{b} / \mathrm{b}=\left(\mathrm{b}_{1}, \mathrm{~b}_{2}, \ldots, \mathrm{b}_{\mathrm{i}}, \ldots\right), \mathrm{b}_{\mathrm{i}} \in[0,1], \forall \mathrm{i}\right.$ such that $\left.\mathrm{b} \leq \mathrm{A}(\mathrm{e})\right\}$.

Then $A_{t}$ is a subgroup of $B_{t}$.

Let $y \in A_{t}$ and $x \in B_{t}$.

Then $\mathrm{A}(\mathrm{y}) \geq \mathrm{t}$ and $\mathrm{B}(\mathrm{x}) \geq \mathrm{t}$

By the hypothesis, $\mathrm{A}\left(\mathrm{xyx}^{-1}\right) \geq \min \{\mathrm{A}(\mathrm{y}), \mathrm{B}(\mathrm{x})\}$

$\geq \min \{t, t\}$, since by (1)

That is, $\mathrm{A}\left(\mathrm{xyx}^{-1}\right) \geq \mathrm{t}$

$$
=\mathrm{t}
$$

Hence $\mathrm{xyx}^{-1} \in \mathrm{A}_{\mathrm{t}}$

That is, $A_{t}$ is a normal subgroup of $B_{t}$

Conversely, Suppose $A_{t}$ is a normal subgroup of $B_{t}, \forall t \in\left\{b / b=\left(b_{1}, b_{2}, \ldots, b_{i}, \ldots\right), b_{i} \in[0,1], \forall i\right.$ such that $\mathrm{b} \leq \mathrm{A}(\mathrm{e})\}$

Let $\mathrm{A}(\mathrm{y})=\mathrm{t} ; \mathrm{B}(\mathrm{x})=\mathrm{b}$ and suppose that $\mathrm{b} \geq \mathrm{t}$

Then this implies that $\mathrm{B}(\mathrm{x}) \geq \mathrm{t}$

$$
\begin{aligned}
& \Rightarrow \mathrm{x} \in \mathrm{B}_{\mathrm{t}} \\
& \Rightarrow \mathrm{xyx}^{-1} \in \mathrm{A}_{\mathrm{t}} \text { since by the hypothesis. }
\end{aligned}
$$

Thus, $\Rightarrow \mathrm{A}\left(\mathrm{xyx}^{-1}\right) \geq \mathrm{t}=\min \{\mathrm{t}, \mathrm{b}\}$, since by $(2)$

$\Rightarrow \mathrm{A}\left(\mathrm{xyx}^{-1}\right) \geq \min \{\mathrm{A}(\mathrm{y}), \mathrm{B}(\mathrm{x})\}$, since by $(2)$

$\Rightarrow \mathrm{A}$ is a normal multi-fuzzy subgroup of $\mathrm{B}$, since by the definition 3.2

Suppose $\mathrm{b}<\mathrm{t} \Rightarrow \mathrm{b}<\mathrm{A}(\mathrm{y})$, since by (2)

$$
\begin{aligned}
& \Rightarrow \mathrm{A}(\mathrm{y})>\mathrm{b} \\
& \Rightarrow \mathrm{y} \in \mathrm{A}_{\mathrm{b}} \\
& \Rightarrow \mathrm{xyx}^{-1} \in \mathrm{A}_{\mathrm{b}}, \mathrm{A}_{\mathrm{b}} \text { is a normal subgroup of } \mathrm{B}_{\mathrm{b}} \text {, by the hypothesis. } \\
& \Rightarrow \mathrm{A}\left(\mathrm{xyx}^{-1}\right) \geq \mathrm{b}=\min \{\mathrm{b}, \mathrm{t}\} \\
& \Rightarrow \mathrm{A}\left(\mathrm{xyx}^{-1}\right) \geq \min \{\mathrm{B}(\mathrm{x}), \mathrm{A}(\mathrm{y})\} \text {, since by }(2) \\
& \Rightarrow A \text { is a normal multi-fuzzy subgroup of } B
\end{aligned}
$$

Therefore, from I and II, we get the proof and hence the Theorem.

3.3 Theorem: Let $A, B \in M F(G)$ and $A$ be a normal multi-fuzzy subgroup of $B$. Then $A_{*}$ is a normal subgroup of $\mathrm{B}_{*}$ and $\mathrm{A}^{*}$ is a normal subgroup of $\mathrm{B}^{*}$.

Proof: If $\mathrm{x} \in \mathrm{A}_{*}, \mathrm{y} \in \mathrm{B}_{*}$ and $\mathrm{A}$ be a normal multi-fuzzy subgroup of $\mathrm{B}$, then this implies that $\mathrm{A}\left(\mathrm{y}^{-1} \mathrm{xy}\right) \geq$ $\min \{\mathrm{A}(\mathrm{x}), \mathrm{B}(\mathrm{y})\}$

$\Rightarrow \mathrm{A}\left(\mathrm{y}^{-1} \mathrm{xy}\right)=\min \{\mathrm{A}(\mathrm{e}), \mathrm{B}(\mathrm{e})\}$

$\Rightarrow \mathrm{A}\left(\mathrm{y}^{-1} \mathrm{xy}\right)=\mathrm{A}(\mathrm{e})$

$\Rightarrow \mathrm{A}_{*}$ is a normal subgroup of $\mathrm{B}_{*}$

Similarly, If $\mathrm{x} \in \mathrm{A}^{*}, \mathrm{y} \in \mathrm{B}^{*}$ and $\mathrm{A}$ be a normal multi-fuzzy subgroup of $\mathrm{B}$, then this implies that

$\mathrm{A}\left(\mathrm{y}^{-1} \mathrm{xy}\right) \geq \min \{\mathrm{A}(\mathrm{x}), \mathrm{B}(\mathrm{y})\}$

$\Rightarrow \mathrm{A}\left(\mathrm{y}^{-1} \mathrm{xy}\right)>0$, since $\mathrm{A}(\mathrm{x}), \mathrm{B}(\mathrm{y})>0$

$\Rightarrow \mathrm{A}^{*}$ is a normal subgroup of $\mathrm{B}^{*}$ and hence the Theorem.

3.4 Theorem: If $A \in N M F(G)$ and $B \in M F(G)$, then $(A \cap B)$ is a normal multi-fuzzy subgroup of $B$.

Proof: Clearly, $A \cap B \in M F(G)$ and $A \cap B \subseteq B$.

Now, $\forall \mathrm{x}, \mathrm{y} \in \mathrm{G},(\mathrm{A} \cap \mathrm{B})\left(\mathrm{xyx}^{-1}\right)=\min \left\{\mathrm{A}\left(\mathrm{xyx}^{-1}\right), \mathrm{B}\left(\mathrm{xyx}^{-1}\right)\right\}$

$$
\begin{aligned}
& =\min \left\{A(y), B\left(x^{-1}\right)\right\}, \text { since } A \in N M F(G) \\
& \geq \min \left\{A(y), \min \left\{B(x), B(y), B\left(x^{-1}\right)\right\}\right\} \\
& =\min \{A(y), \min \{B(x), B(y)\}\} \\
& =\min \{\min \{A(y), B(y)\}, B(x)\} \\
& =\min \{(A \cap B)(y), B(x)\}
\end{aligned}
$$

This implies that $(A \cap B)$ is a normal multi-fuzzy subgroup of $B$, since by the definition of 3.2. and hence the Theorem.

3.5 Theorem: Let $A, B, C \in M F(G)$ be such that $A$ and $B$ are normal multi-fuzzy subgroups of $C$. Then $(A \cap B)$ is a normal multi-fuzzy subgroup of $\mathrm{C}$. 
Proof: Observe that $(A \cap B) \in M F(G)$ and $(A \cap B) \subseteq C$. Now, $(\mathrm{A} \cap \mathrm{B})\left(\mathrm{xyx}^{-1}\right)=\min \left\{\mathrm{A}\left(\mathrm{xyx}^{-1}\right), \mathrm{B}\left(\mathrm{xyx}^{-1}\right)\right\}$

$\geq \min \{\min \{\mathrm{A}(\mathrm{y}), \mathrm{C}(\mathrm{x})\}, \min \{\mathrm{B}(\mathrm{y}), \mathrm{C}(\mathrm{x})\}\}$, since $\mathrm{A}$ and $\mathrm{B}$ are normal multi-fuzzy subgroups of $\mathrm{C}$.

$\geq \min \{\min \{\mathrm{A}(\mathrm{y}), \mathrm{B}(\mathrm{y})\}, \mathrm{C}(\mathrm{x})\}$

$=\min \{(\mathrm{A} \cap \mathrm{B})(\mathrm{y}), \mathrm{C}(\mathrm{x})\}$

Therefore, $(A \cap B)$ is a normal multi-fuzzy subgroup of $C$, since by the definition 3.2 and hence the Theorem.

\section{Normal multi-anti fuzzy subgroup of the multi-anti fuzzy subgroup}

In this section, we introduce the concept of normal multi-anti fuzzy subgroup of a multi-anti fuzzy subgroup and examine its basic properties.

4.1 Definition A multi-anti fuzzy subgroup $A$ of a group $G$ is called normal if for each $x \in G$,

$$
\mathrm{A}(\mathrm{x}) \geq \max _{\mathrm{g} \in \mathrm{G}}\left\{\mathrm{A}\left(\mathrm{gxg}^{-1}\right)\right\}
$$

4.2 Definition Let $A, B \in M A F(G)$ and $A \subseteq B$. Then $A$ is called a normal multi-anti fuzzy subgroup of the multianti fuzzy subgroup $\mathrm{B}$, written as $\mathrm{A} \Delta \mathrm{B}$, if $\mathrm{A}\left(\mathrm{xyx}^{-1}\right) \leq \max \{\mathrm{A}(\mathrm{y}), \mathrm{B}(\mathrm{x})\}, \forall \mathrm{x}, \mathrm{y} \in \mathrm{G}$.

Remarks: The following statements are immediate from the above definition :

1. Every multi-anti fuzzy subgroup is a normal multi-anti fuzzy subgroup of itself.

2. $\mathrm{A} \in \operatorname{MAFP}(\mathrm{G})$ is a normal multi-anti fuzzy subgroup of $\mathrm{G} \Leftrightarrow \mathrm{A}$ is a normal multi-anti fuzzy subgroup of the multi-anti fuzzy subgroup $1_{\mathrm{G}}$

Notations: The following notations to be used in this paper with the following meaning:

1. $\operatorname{MAF}(\mathrm{G})$ is the set of all multi-anti fuzzy subgroups of a group $\mathrm{G}$

2. $\operatorname{NMAF}(\mathrm{G})$ is the set of all normal multi-anti fuzzy subgroups of a group $\mathrm{G}$

4.3 Definition Let $\mu$ be any anti-fuzzy subgroup of a group $G$ and $x \in G$. The fuzzy subsets $\mu(e)_{\{x\}^{\circ}} \mu$ and $\mu^{\circ} \mu(\mathrm{e})_{\{\mathrm{x}\}}$ are referred to as the left fuzzy coset and right fuzzy coset of $\mu$ with respect to $\mathrm{x}$ and written as $\mathrm{x} \mu$ and $\mu \mathrm{x}$, respectively.

4.4 Definition Let $A$ be a multi-anti fuzzy subgroup of a group $G$ and $x \in G$. The multi-fuzzy sets $A(e)_{\{x\}^{\circ}} A$ and $\mathrm{A} \circ \mathrm{A}(\mathrm{e})_{\{\mathrm{x}\}}$ are referred to as the left multi-fuzzy coset and right multi-fuzzy coset of $\mathrm{A}$ with respect to $\mathrm{x}$ and written as xA and Ax respectively.

Remark: If $A \in \operatorname{NMAF}(G)$ is a normal multi-anti fuzzy subgroup of a group $G$, then the left multi-fuzzy coset $\mathrm{xA}$ is just the right multi-fuzzy coset Ax. Thus, in this case, we call xA as a multi-fuzzy coset for short.

4.1 Theorem: Let $A, B \in M A F(G)$ and $A \subseteq B$. Then the following assertions are equivalent:

1. A is a normal multi-anti fuzzy subgroup of $B$

2. $\quad \mathrm{A}(\mathrm{yx}) \leq \max \{\mathrm{A}(\mathrm{xy}), \mathrm{B}(\mathrm{y})\}, \forall \mathrm{x}, \mathrm{y} \in \mathrm{G}$

3. $\quad \mathrm{A}(\mathrm{e})_{\{\mathrm{x}\}}{ }^{\circ} \mathrm{A} \subseteq\left(\mathrm{A} \circ \mathrm{A}(\mathrm{e})_{\{\mathrm{x}\}}\right) \cup \mathrm{B}, \forall \mathrm{x} \in \mathrm{G}$.

Proof: $(1) \Rightarrow(2)$

Since A is a normal multi-anti fuzzy subgroup of $B$,

$$
\begin{aligned}
\mathrm{A}(\mathrm{yx}) & =\mathrm{A}\left(\mathrm{yxyy}^{-1}\right) \\
& =\mathrm{A}\left(\mathrm{y}(\mathrm{xy}) \mathrm{y}^{-1}\right) \\
& \leq \max \{\mathrm{A}(\mathrm{xy}), \mathrm{B}(\mathrm{y})\}, \forall \mathrm{x}, \mathrm{y} \in \mathrm{G}, \text { since by the definition } 4.2 .
\end{aligned}
$$

Proof: $(2) \Rightarrow(1)$

$$
\begin{aligned}
\mathrm{A}\left(\mathrm{xyx}^{-1}\right) & =\mathrm{A}\left(\mathrm{x}\left(\mathrm{yx}^{-1}\right)\right) \\
& \leq \max \left\{\mathrm{A}\left(\left(\mathrm{yx} \mathrm{x}^{-1}\right) \mathrm{x}\right), \mathrm{B}(\mathrm{x})\right\}, \text { since by the hypothesis(2). } \\
& =\max \{\mathrm{A}(\mathrm{y}), \mathrm{B}(\mathrm{x})\}
\end{aligned}
$$

That is, A is normal multi-anti fuzzy subgroup of B

That is, $\mathrm{A} \Delta \mathrm{B}$.

Proof: $(2) \Rightarrow(3) \quad \forall z \in G$,

$\left(\mathrm{A}(\mathrm{e})_{\{\mathrm{x}\}^{\circ}} \mathrm{A}\right)(\mathrm{z})=\max \left\{\min \left\{\mathrm{A}(\mathrm{e})_{\{\mathrm{x}\}}(\mathrm{p}), \mathrm{A}(\mathrm{q})\right\} / \mathrm{pq}=\mathrm{z}\right.$ where $\left.\mathrm{p}, \mathrm{q} \in \mathrm{G}\right\}$, since by the definition 2.11

$=\max \left\{\min \left\{A(e)_{\{x\}}(x), A(q)\right\} / x q=z\right\}$, since take $\mathrm{p}=\mathrm{x}$ 
Hence the proof $(2) \Rightarrow(3)$.

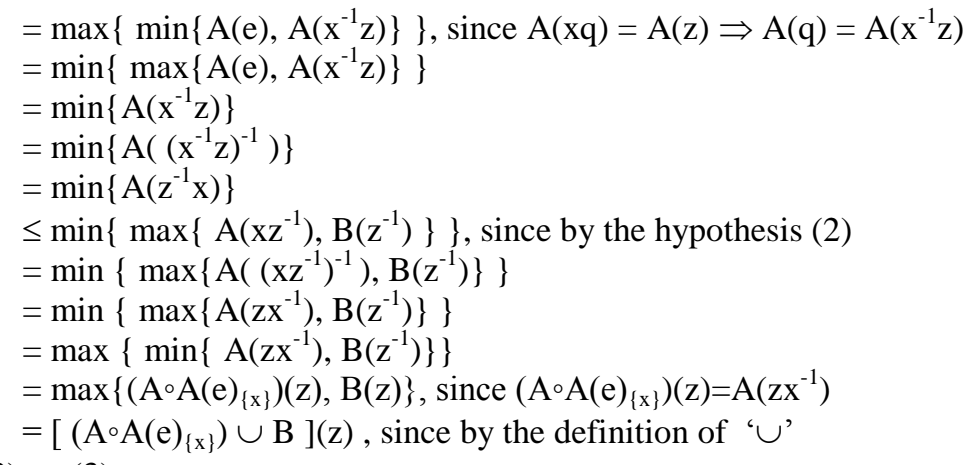

Proof: (3) $\Rightarrow$ (2)

$\forall \mathrm{x}, \mathrm{y} \in \mathrm{G}, \mathrm{A}(\mathrm{yx})=\mathrm{A}\left((\mathrm{yx})^{-1}\right)$

$=\mathrm{A}\left(\mathrm{x}^{-1} \mathrm{y}^{-1}\right)$

$=\left(\mathrm{A}(\mathrm{e})_{\{\mathrm{x}\}^{\circ}} \mathrm{A}\right)\left(\mathrm{y}^{-1}\right)$

$\leq\left(\left(\mathrm{A} \circ \mathrm{A}(\mathrm{e})_{\{\mathrm{x}\}}\right) \cup \mathrm{B}\right)\left(\mathrm{y}^{-1}\right)$, since by the hypothesis (3)

$=\max \left\{\left(\mathrm{A} \circ \mathrm{A}(\mathrm{e})_{\{\mathrm{x}\}}\right)\left(\mathrm{y}^{-1}\right), \mathrm{B}\left(\mathrm{y}^{-1}\right)\right\}$, since by the definition of ' '

$=\max \left\{\mathrm{A}\left(\mathrm{y}^{-1} \mathrm{x}^{-1}\right), \mathrm{B}\left(\mathrm{y}^{-1}\right)\right\}$, since by the definition 2.11

$=\max \left\{\mathrm{A}\left((\mathrm{xy})^{-1}\right), \mathrm{B}(\mathrm{y})\right\}$

$=\max \{\mathrm{A}(\mathrm{xy}), \mathrm{B}(\mathrm{y})\}$

Hence the proof (3) $\Rightarrow(2)$ and hence the Theorem also.

4.2 Theorem: Let $A, B \in \operatorname{MAF}(G)$. Then $A$ is a normal multi-anti fuzzy subgroup of $B \Leftrightarrow A_{t}$ is a normal subgroup of $\mathrm{B}_{\mathrm{t}}, \forall \mathrm{t} \in\left\{\mathrm{b} / \mathrm{b}=\left(\mathrm{b}_{1}, \mathrm{~b}_{2}, \ldots, \mathrm{b}_{\mathrm{i}}, \ldots\right), \mathrm{b}_{\mathrm{i}} \in[0,1], \forall \mathrm{i}\right.$ such that $\left.\mathrm{b} \geq \mathrm{A}(\mathrm{e})\right\}$

Proof: ( $\Rightarrow$ part )

Suppose $\mathrm{A}$ is a normal multi-anti fuzzy subgroup of $\mathrm{B}$.

Let $\mathrm{t} \in\left\{\mathrm{b} / \mathrm{b}=\left(\mathrm{b}_{1}, \mathrm{~b}_{2}, \ldots, \mathrm{b}_{\mathrm{i}}, \ldots\right), \mathrm{b}_{\mathrm{i}} \in[0,1], \forall \mathrm{i}\right.$ such that $\left.\mathrm{b} \geq A(\mathrm{e})\right\}$.

Then $A_{t}$ is a subgroup of $B_{t}$.

Let $y \in A_{t}$ and $x \in B_{t}$

Then $\mathrm{A}(\mathrm{y}) \leq \mathrm{t}$ and $\mathrm{B}(\mathrm{x}) \leq \mathrm{t}$

By the hypothesis, $\mathrm{A}\left(\mathrm{xyx}^{-1}\right) \leq \max \{\mathrm{A}(\mathrm{y}), \mathrm{B}(\mathrm{x})\}$

$$
\leq \max \{t, t\} \text {, since by }(1)
$$

That is, $\mathrm{A}\left(\mathrm{xyx}^{-1}\right) \leq \mathrm{t}$

$$
=\mathrm{t}
$$

Hence $\mathrm{xyx}^{-1} \in \mathrm{A}_{\mathrm{t}}$

That is, $A_{t}$ is a normal subgroup of $B_{t}$

Conversely, Suppose $A_{t}$ is a normal subgroup of $B_{t}, \forall t \in\left\{b / b=\left(b_{1}, b_{2}, \ldots, b_{i}, \ldots\right), b_{i} \in[0,1], \forall i\right.$ such that $\mathrm{b} \geq \mathrm{A}(\mathrm{e})\}$

Let $\mathrm{A}(\mathrm{y})=\mathrm{t} ; \mathrm{B}(\mathrm{x})=\mathrm{b}$ and suppose that $\mathrm{b} \leq \mathrm{t}$

Then this implies that $\mathrm{B}(\mathrm{x}) \leq \mathrm{t}$

$$
\begin{aligned}
& \Rightarrow \mathrm{x} \in \mathrm{B}_{\mathrm{t}} \\
& \Rightarrow \mathrm{xyx}^{-1} \in \mathrm{A}_{\mathrm{t}} \text { since by the hypothesis. }
\end{aligned}
$$

Thus, $\Rightarrow \mathrm{A}\left(\mathrm{xyx}^{-1}\right) \leq \mathrm{t}=\max \{\mathrm{t}, \mathrm{b}\}$, since by $(2)$

$\Rightarrow \mathrm{A}\left(\mathrm{xyx}^{-1}\right) \leq \max \{\mathrm{A}(\mathrm{y}), \mathrm{B}(\mathrm{x})\}$, since by $(2)$

$\Rightarrow \mathrm{A}$ is a normal multi-anti fuzzy subgroup of $\mathrm{B}$, since by the definition 4.2

Suppose $\mathrm{b}>\mathrm{t} \Rightarrow \mathrm{b}>\mathrm{A}(\mathrm{y})$, since by (2)

$$
\begin{aligned}
& \Rightarrow \mathrm{A}(\mathrm{y})<\mathrm{b} \\
& \Rightarrow \mathrm{y} \in \mathrm{A}_{\mathrm{b}} \\
& \Rightarrow \mathrm{xyx} \mathrm{x}^{-1} \in \mathrm{A}_{\mathrm{b}}, \text { since } \mathrm{A}_{\mathrm{b}} \text { is a normal subgroup of } \mathrm{B}_{\mathrm{b}}, \text { by the hypothesis. } \\
& \Rightarrow \mathrm{A}\left(\mathrm{xyx}^{-1}\right) \leq \mathrm{b}=\max \{\mathrm{b}, \mathrm{t}\} \\
& \Rightarrow \mathrm{A}\left(\mathrm{xyx}^{-1}\right) \leq \max \{\mathrm{B}(\mathrm{x}), \mathrm{A}(\mathrm{y})\} \text {, since by (2) } \\
& \Rightarrow \mathrm{A} \text { is a normal multi-anti fuzzy subgroup of } \mathrm{B}, \text { since by the definition } 4.2
\end{aligned}
$$

Therefore, from I and II, we get the proof and hence the Theorem .

4.3 Theorem: Let $A, B \in M A F(G)$ and $A$ be a normal multi-anti fuzzy subgroup of $B$. Then $A_{*}$ is a normal subgroup of $\mathrm{B}_{*}$ and $\mathrm{A}^{*}$ is a normal subgroup of $\mathrm{B}^{*}$. 
Proof: If $\mathrm{x} \in \mathrm{A}_{*}, \mathrm{y} \in \mathrm{B}_{*}$ and $\mathrm{A}$ be a normal multi-anti fuzzy subgroup of $\mathrm{B}$, then this implies that $\mathrm{A}\left(\mathrm{y}^{-1} \mathrm{xy}\right) \leq$ $\max \{\mathrm{A}(\mathrm{x}), \mathrm{B}(\mathrm{y})\}$

$\Rightarrow \mathrm{A}\left(\mathrm{y}^{-1} \mathrm{xy}\right)=\max \{\mathrm{A}(\mathrm{e}), \mathrm{B}(\mathrm{e})\}$

$\Rightarrow \mathrm{A}\left(\mathrm{y}^{-1} \mathrm{xy}\right)=\mathrm{B}(\mathrm{e})$

$\Rightarrow A_{*}$ is a normal subgroup of $B_{*}$

Similarly, If $\mathrm{x} \in \mathrm{A}^{*}, \mathrm{y} \in \mathrm{B}^{*}$ and $\mathrm{A}$ be a normal multi-anti fuzzy subgroup of $\mathrm{B}$, then this implies that $\mathrm{A}\left(\mathrm{y}^{-1} \mathrm{xy}\right) \leq$ $\max \{\mathrm{A}(\mathrm{x}), \mathrm{B}(\mathrm{y})\}$

$\Rightarrow \mathrm{A}\left(\mathrm{y}^{-1} \mathrm{xy}\right)>0$, since $\mathrm{A}(\mathrm{x}), \mathrm{B}(\mathrm{y})>0$

$\Rightarrow \mathrm{A}^{*}$ is a normal subgroup of $\mathrm{B}^{*}$ and hence the Theorem.

4.4 Theorem: If $A \in \operatorname{NMAF}(G)$ and $B \in M A F(G)$, then $(A \cup B)$ is a normal multi-anti fuzzy subgroup of $B$.

Proof: Clearly, $A \cup B \in M A F(G)$ and $B \subseteq A \cup B$.

Now, $\forall \mathrm{x}, \mathrm{y} \in \mathrm{G}, \quad(\mathrm{A} \cup \mathrm{B})\left(\mathrm{xyx}^{-1}\right)=\max \left\{\mathrm{A}\left(\mathrm{xyx}^{-1}\right), \mathrm{B}\left(\mathrm{xyx}^{-1}\right)\right\}$

$=\max \left\{\mathrm{A}(\mathrm{y}), \mathrm{B}\left(\mathrm{xyx}^{-1}\right)\right\}$, since $\mathrm{A} \in \operatorname{NMAF}(\mathrm{G})$

$\leq \max \left\{\mathrm{A}(\mathrm{y}), \max \left\{\mathrm{B}(\mathrm{x}), \mathrm{B}(\mathrm{y}), \mathrm{B}\left(\mathrm{x}^{-1}\right)\right\}\right\}$

$=\max \{\mathrm{A}(\mathrm{y}), \max \{\mathrm{B}(\mathrm{x}), \mathrm{B}(\mathrm{y})\}\}$

$=\max \{\max \{\mathrm{A}(\mathrm{y}), \mathrm{B}(\mathrm{y})\}, \mathrm{B}(\mathrm{x})\}$

$=\max \{(\mathrm{A} \cup \mathrm{B})(\mathrm{y}), \mathrm{B}(\mathrm{x})\}$

This implies that $(A \cup B)$ is a normal multi-anti fuzzy subgroup of $B$, since by the definition 4.2 and hence the Theorem.

4.5 Theorem: Let $A, B, C \in M A F(G)$ be such that A and B are normal multi-anti fuzzy subgroups of C. Then $(A \cup B)$ is a normal multi-anti fuzzy subgroup of $C$.

Proof: Observe that $(A \cup B) \in \operatorname{MAF}(G)$ and $(A \cup B) \subseteq C$. Now, $(\mathrm{A} \cup \mathrm{B})\left(\mathrm{xyx}^{-1}\right)=\max \left\{\mathrm{A}\left(\mathrm{xyx}^{-1}\right), \mathrm{B}\left(\mathrm{xyx}^{-1}\right)\right\}$ subgroups of $\mathrm{C}$.

$\leq \max \{\max \{\mathrm{A}(\mathrm{y}), \mathrm{C}(\mathrm{x})\}, \max \{\mathrm{B}(\mathrm{y}), \mathrm{C}(\mathrm{x})\}\}$, since $\mathrm{A}$ and $\mathrm{B}$ are normal multi-anti fuzzy

$$
\begin{aligned}
& \leq \max \{\max \{\mathrm{A}(\mathrm{y}), \mathrm{B}(\mathrm{y})\}, \mathrm{C}(\mathrm{x})\} \\
& =\max \{(\mathrm{A} \cup \mathrm{B})(\mathrm{y}), \mathrm{C}(\mathrm{x})\}
\end{aligned}
$$

Therefore, $(A \cup B)$ is a normal multi-anti fuzzy subgroup of $C$, since by the definition 4.2 and hence the Theorem.

\section{Conclusion}

In this paper we discussed normal multi-fuzzy subgroup of multi-fuzzy subgroup and normal multianti fuzzy subgroup of multi-anti fuzzy subgroup. Multi-fuzzy cosets are very useful for the theory of multifuzzy set, multi-fuzzy subgroup and multi-anti fuzzy subgroups.

\section{Journal Papers:}

\section{REFERENCES}

[1] Das. P.S., Fuzzy groups and level subgroups, Journal of Mathematical Analysis and Applications, 84 (1981), $264-269$.

[2] Liu W.J., Fuzzy invariant subgroup and fuzzy ideal, Fuzzy Sets and Systems, 8(1981),133-139.

[3] Mukharjee N.P. and Bhattacharya P., Fuzzy normal subgroups and fuzzy cosets, Information Sciences, 34 (1984), $225-239$.

[4] Muthuraj.R and Balamurugan.S, Multi-anti fuzzy group and its Lower level subgroups, Int. Journal of Engineering Research and Applications, Vol. 3, Issue 6, Nov-Dec 2013, pp.1498-1501.

[5] Muthuraj.R, Sitharselvam.P.M and Muthuraman.M.S, Anti Q-fuzzy group and its Lower level subgroups, International Journal of Computer Applications(0975-8887), Volume 3-No. 3,June2010,16-20.

[6] Muthuraj.R and Balamurugan.S, Multi-fuzzy group and its level subgroups, Gen. Math. Notes, Vol. 17,No. 1, July, 2013 , pp. 74-81.

[7] Palaniappan.N, Muthuraj.R, Anti fuzzy group and its Lower level subgroups, Antartica J.Math., 1 (1)(2004), 71-76.

[8] Rosenfeld.A, fuzzy groups, J. math. Anal.Appl. 35 (1971), 512-517.

[9] Sabu.S and Ramakrishnan.T.V, Multi-fuzzy sets, International Mathematical Forum, 50 (2010), 2471-2476.

[10] Sabu.S and Ramakrishnan.T.V, Multi-fuzzy subgroups, Int. J. Contemp. Math. Sciences, Vol.6, 8 (2011), $365-372$.

[11] Zadeh.L.A, Fuzzy sets, Information and Control, 8 (1965), 338-353. 